\title{
Refinement of Intraocular Pressure Measurements made by Ocular Response Analyzer following Laser in Situ Keratomileusis using M2 90 Moria Microkeratome for Egyptian Myopic and Astigmatic Patients
}

\author{
Tamer Adel Refai, Olfat A. Hassanin
}

Refractive Unit, Ophthalmology Department, Research Institute of Ophthalmology, Giza, Egypt

Type of article: Original

\begin{abstract}
Introduction: The Goldmann applanation tonometer readings were noted to be markedly reduced after Lasik surgery using a thin flap technique which is widely used nowadays, to correct a wide range of myopia and astigmatism. The Ocular Response Analyzer (ORA) is considered one of the important tools for refinement of Intraocular Pressure (IOP) measurements. The aim of this study is to evaluate and refine ORA measurements for IOP changes post- M2 90 Moria microkeratome Lasik procedure for Egyptian myopic and astigmatic patients trying to aid in glaucoma diagnosis and management.

Methods: Thirty-five eyes of nineteen Egyptian patients with myopia or myopic astigmatism who had undergone Lasik procedure using M2 90 Moria microkeratome were included in this consecutive case series study. All cases were subjected to full ophthalmological examination including uncorrected and best corrected visual acuity, refraction, slit lamp examination, Scheimpflug imaging and ORA (Reichert Ophthalmic Instruments, Inc., Buffalo, NY, USA). The refractive errors were measured using an auto refractometer and were confirmed by trial. For the ocular response analyzer, the Goldmann-correlated IOP measurement (IOPg) which simulates IOP measured by Goldmann tonometer and the Corneal-Compensated Intraocular Pressure (IOPcc) that takes corneal biomechanical properties into consideration were reported as well as the Corneal Hysteresis $(\mathrm{CH})$ and the Corneal Resistance Factor (CRF). Cases were examined preoperatively and again about one month after Lasik, after stabilization of eye condition. The collected data were tabulated and analysed with the suitable statistical methods. The mean values and standard deviation were calculated for quantitative data. Comparison tests ( $\mathrm{t}$-test) and correlation tests (Pearson) were also performed.

Results: In our study, involving M2 90 Moria microkeratome Lasik procedure, a highly significant post-Lasik reduction in IOPg $(\mathrm{t}$-test $=8.62(\mathrm{p}<0.01)$, and a statistically significant reduction in IOPcc $(\mathrm{t}$-test $=3.37(\mathrm{p}<0.05)$ by ocular response analyzer. The average post-Lasik reduction in IOP in $\mathrm{mmHg}$ was $4.84 \pm 2.82$ for IOPg and $2.23 \pm 3.51$ for IOPcc. A statistically significant correlation $(\mathrm{p}<0.05)$ existed between post-Lasik reduction of IOPg and ablation depth as well as preoperative spherical equivalent. A non-significant correlation existed between post-Lasik reduction of IOPcc and both of ablation depth and preoperative spherical equivalent.

Conclusions: Following Lasik procedure using M2 90 Moria microkeratome, the IOPcc values by ORA were closer to the preoperative values than the IOPg values and the reduction of IOPcc values was not affected by ablation depth (i.e. preoperative spherical equivalent). Therefore, it is advisable to use the IOPcc values by ORA when evaluating post-Lasik patients for glaucoma diagnosis and management, but with the addition of the average value for post-Lasik reduction which in the study was $2.23 \pm 3.51 \mathrm{mmHg}$.

Keywords: Thin flap Lasik, the Goldmann-correlated IOP, Corneal-Compensated Intraocular Pressure, ablation depth, Egypt
\end{abstract}

\section{Introduction}

\subsection{Background and statement of the problem}

Measurement of intraocular pressure (IOP) is a part of routine ophthalmologic examination and is important in the management and follow-up of patients with glaucoma (1). The Goldmann applanation tonometer (GAT) is

\section{Corresponding author:}

Tamer Adel Refai, Refractive Unit, Ophthalmology Department, Research Institute of Ophthalmology, Giza, Egypt. Tel: +20.1002955180, E-mail: tamerrefai@hotmail.com

Received: July 04, 2016, Accepted: October 17, 2016, Published: December 2016

iThenticate screening: October 17, 2016, English editing: November 18, 2016, Quality control: December 02, 2016

(C) 2016 The Authors. This is an open access article under the terms of the Creative Commons Attribution-NonCommercialNoDerivs License, which permits use and distribution in any medium, provided the original work is properly cited, the use is non-commercial and no modifications or adaptations are made. 
considered as the gold standard for clinical IOP measurement (2). However, its accuracy is affected by the interindividual variation in corneal geometric properties, such as thickness $(3,4)$ and curvature $(3,5)$ as well as rigidity $(6,7)$. LASIK had become the technique of choice for treatment of wide range of myopia, offering quicker visual recovery and relatively pain-free experience (8). However, reduction of Goldmann Applanation tonometer readings was noted after Lasik procedure, probably related to reduction in corneal thickness (9) and biomechanics (10). The ocular response analyzer is considered one of the important tools for refinement of intraocular pressure measurements $(11,12)$, where it calculates Goldmann-correlated and corneal-compensated IOP estimates (IOPg and IOPcc respectively). IOPg is considered analogous to standard non-contact tonometry IOP measurements, while IOPcc is an IOP estimate that uses a mathematical correction to minimise its corneal dependence (13).

\subsection{Objectives}

The aim of this work was to evaluate the changes in the IOP measurements by ocular response analyzer following Lasik procedure, using the widely used thin flap M2 90 Moria microkeratome for a wide range of myopic and astigmatic ablation depths, aiming to provide a finer refinement of IOP measurement post-Lasik procedure trying to aid in glaucoma diagnosis and management.

\section{Material and Methods}

Thirty-five eyes of nineteen Egyptian patients with myopia or myopic astigmatism who had undergone Lasik procedure using M2 90 Moria microkeratome between 2014 and 2015 were included in this consecutive case series study. All cases were subjected to full ophthalmological examination including uncorrected and best corrected visual acuity, refraction, slit lamp examination, Scheimpflug imaging (i.e. Pentacam, ALLEGRO Oculyzer Version 1074; Allegro, Germany) and ORA (Reichert Ophthalmic Instruments, Inc., Buffalo, NY, USA). The refractive errors were measured using an auto refractometer and confirmed by trial. The central corneal thickness (CCT) as well as the flattest and steepest keratometry readings within the central $3 \mathrm{~mm}$ ring, were obtained from the Pentacam. For the ocular response analyzer, the Goldmann-correlated IOP measurement IOPg which simulates IOP measured by Goldmann tonometer and the IOPcc that takes corneal biomechanical properties into consideration were reported, as well as the $\mathrm{CH}$ which is a measure of viscous damping in the cornea and the CRF, which is a measure of the total viscoelastic response of the cornea. The following were set as the exclusion criteria: 1) Thin cornea (less than 500 microns by Pentacam), 2) Keratoconus and other ectatic disorders, 3) Signs of previous viral keratitis or iridocyclitis, 4) Glaucoma, 5) Autoimmune and systemic collagen disease e.g. rheumatoid arthritis, SLE, 6) pregnancy. The Lasik procedure consisted of tropical anesthesia before the operation, sterilizing the eyelids, speculum application, corneal marking, applying the Moria M2 microkratome over the cornea to create a superior hinged corneal flap, ablation by the Allegretto Wave Light Eye-Q 1010 (400 Hertz) and irrigation of the stromal bed using balanced salt solution (BSS). Finally, the flap was repositioned painted by a jet of air and its alignment was checked by preoperative corneal marks alignment. After operation, patients received antibiotics, corticosteroid eye drops and preservative-free artificial tears eye drops. The collected data were tabulated and analysed with the suitable statistical methods. The mean values and standard deviation were calculated for quantitative data. Comparison tests ( $\mathrm{t}$ test) and correlation tests (Pearson) were also performed.

\section{Results}

\subsection{General findings}

Thirty-five (35) eyes of nineteen (19) patients were included in the study. There were 14 eyes of male patients and 21 eyes of female patients. The age ranged from 19-42years (mean 30.14 \pm 7.09 ). The flattest keratometric readings (K1) ranged from 39-45 Diopters (mean 43 \pm 1.57 ), the steepest keratometric readings (K2) ranged from 41.1-47.2 Diopters (mean 44.29 \pm 1.54 ), and the average keratometric readings $(\mathrm{Km})$ ranged from 40.1-45.85 Diopters (mean 43.65 1.49). The Central corneal thickness (CCT) ranged from 507-587 $(\mu)$ (mean 547.43 \pm 24.14 ). The sphere ranged from 0.25 to -9 Diopters (mean $-3.83 \pm 2.25$ ), the cylinder ranged from -0.25 to -3.5 Diopters (mean $1.41 \pm 0.88$ ) and the spherical equivalent ranged from -0.88 to -10 Diopters (mean $-4.49 \pm 2.20$ ). The best-corrected visual acuity in Snellen lines ranged from 0.2-1(mean 0.76 \pm 0.25$)$. The ablation depth ranged from 25-154 ( $\mu$ ) (mean

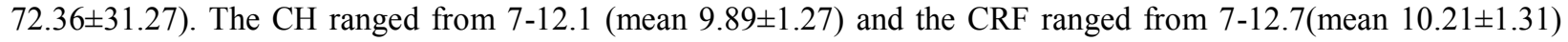
(Table 1). The IOPg by ORA decreased from a mean value of $17.1 \pm 2.75$ preoperatively to $12.26 \pm 2.81$ postoperatively (after thin flap-Lasik), with t-test showing a value of $8.62(\mathrm{p}<0.01)$ denoting a highly significant reduction among patients under study (Table 2). The IOPcc by ORA decreased from a mean value of $18.03 \pm 2.88$ preoperatively to $15.80 \pm 2.88$ post-operatively (after thin flap-Lasik) with t-test showing a value of $3.37(\mathrm{p}<0.05)$ denoting a statistically significant reduction among patients under study (Table 2). The CH by ORA decreased from a mean value of $9.89 \pm 1.27$ preoperatively to $7.9 \pm 1.39$ post-operatively (after thin flap-Lasik) with t-test showing a 
value of $7.16(\mathrm{p}<0.05)$ denoting a statistically significant reduction among patients under study (Table 2$)$. The CRF by ORA decreased from a mean value of $10.21 \pm 1.31$ preoperatively to $7.58 \pm 1.32$ post-operatively (after thin flapLasik), with t-test showing a value of $8.62(\mathrm{p}<0.01)$ denoting a highly significant reduction among patients under study (Table 2). The average reduction in IOPg by ORA ranged from $0.2-12.4 \mathrm{mmhg}$ (mean value $4.84 \pm 2.82$ ). The average reduction in IOPcc by ORA ranged from $-2.9-3.51 \mathrm{mmhg}$ (mean value $2.23 \pm 3.51$ ).

Table 1. Demographic data

\begin{tabular}{|l|l|l|}
\hline Item & Mean \pm SD & Range \\
\hline Age (Years) & $30.14 \pm 7.09$ & $19-42$ \\
\hline K1 (D) & $43 \pm 1.57$ & $39-45$ \\
\hline K2 (D) & $44.29 \pm 1.54$ & $41.1-47.2$ \\
\hline Km (D) & $43.65 \pm 1.49$ & $40.1-45.85$ \\
\hline Central corneal thickness $(\mu)$ & $547.43 \pm 24.14$ & $507-587$ \\
\hline Sphere (D) & $-3.83 \pm 2.25$ & 0.25 to -9 \\
\hline Cylinder (D) & $-1.41 \pm 0.88$ & -0.25 to -3.5 \\
\hline Preoperative spherical equivalent (D) & $-4.49 \pm 2.20$ & -0.88 to -10 \\
\hline Ablation depth $(\mu)$ & $72.36 \pm 31.27$ & $25-154$ \\
\hline Corneal hysteresis $(\mathrm{CH})$ & $9.89 \pm 1.27$ & $7-12.1$ \\
\hline Corneal Resistance Factor (CRF) & $10.21 \pm 1.31$ & $7-12.7$ \\
\hline BCVA in Snellen lines & $0.76 \pm 0.25$ & $0.2-1$ \\
\hline
\end{tabular}

Table 2. Showing the mean value and standard deviation for Ocular Response Analyzer parameters both pre and post-thin flap Lasik and their comparison by t-test and significance among patients under study

\begin{tabular}{|l|l|l|l|l|}
\hline Variable & $\begin{array}{l}\text { Preoperative } \\
(\text { Mean } \pm \text { SD) }\end{array}$ & $\begin{array}{l}\text { Postoperative } \\
(\text { Mean } \pm \text { SD) }\end{array}$ & t-test & p-value \\
\hline IOPg $(\mathrm{mmHg})$ & $17.1 \pm 2.75$ & $12.26 \pm 2.81$ & 8.62 & $<0.01$ \\
\hline IOPcc $(\mathrm{mmHg})$ & $18.03 \pm 2.88$ & $15.80 \pm 2.88$ & 3.37 & $<0.05$ \\
\hline Corneal hysteresis $(\mathrm{CH})$ & $9.89 \pm 1.27$ & $7.9 \pm 1.39$ & 7.16 & $<0.05$ \\
\hline Corneal Resistance Factor $(\mathrm{CRF})$ & $10.21 \pm 1.31 \mathrm{D}$ & $7.58 \pm 1.32 \mathrm{D}$ & 10.35 & $<0.01$ \\
\hline
\end{tabular}

\subsection{Post-Lasik reduction of Goldmann-correlated IOP (IOPg)}

A statistically significant correlation $(\mathrm{r}=0.16, \mathrm{p}<0.05)$ existed between post-Lasik reduction of IOPg and ablation depth among patients under study. A statistically significant correlation $(r=0.17, p<0.05)$ existed between post-Lasik reduction of IOPg and preoperative spherical equivalent among patients under study. A non-significant correlation $(\mathrm{r}=-0.09, \mathrm{p}>0.05)$ existed between post-Lasik reduction of IOPg and $\mathrm{CH}$ among patients under study. A nonsignificant correlation $(\mathrm{r}=-0.07, \mathrm{p}>0.05)$ existed between post-Lasik reduction of IOPg and CRF among patients under study (Table 3).

Table 3. Correlation (Pearson test) between post-thin flap Lasik reduction in Goldmann-correlated IOP (IOPg) and Corneal-Compensated Intraocular Pressure (IOPcc) by Ocular Response Analyzer and various parameters among patients under study

\begin{tabular}{|l|l|l|}
\hline Correlation between items & $\mathrm{r}$ & $\mathrm{p}$-value \\
\hline IOPgREd VS ABL Depth & 0.16 & $<0.05$ \\
\hline IOPgREd VS Sph.Eq & 0.17 & $<0.05$ \\
\hline IOPgREd VS CHred & -0.09 & $>0.05$ \\
\hline IOPgREd VS CRFred & -0.07 & $>0.05$ \\
\hline IOPccREd VS ABL Depth & -0.20 & $>0.05$ \\
\hline IOPccREd VS Sph.Eq & -0.19 & $>0.05$ \\
\hline IOPccREd VS CHred & -0.51 & $>0.05$ \\
\hline IOPccREd VS CRFred & -0.54 & $>0.05$ \\
\hline
\end{tabular}

\subsection{Post-Lasik reduction of Corneal-Compensated Intraocular Pressure (IOPcc)}

A non-significant correlation ( $\mathrm{r}=-0.20, \mathrm{p}>0.05)$ existed between post-Lasik reduction of IOPcc and ablation depth among patients under study. A non-significant correlation $(\mathrm{r}=-0.19, \mathrm{p}>0.05)$ existed between post-Lasik reduction of IOPcc and preoperative spherical equivalent among patients under study. A non-significant correlation $(\mathrm{r}=-0.51$, 
$\mathrm{p}>0.05)$ existed between post-Lasik reduction of IOPcc and $\mathrm{CH}$ among patients under study. A non-significant correlation $(\mathrm{r}=-0.54, \mathrm{p}>0.05)$ existed between post-Lasik reduction of IOPcc and CRF among patients under study (Table 3).

\section{Discussion}

Following Lasik surgery, the Goldmann applanation tonometry readings were proven to be underestimated, probably due to reduction of central corneal thickness and rigidity, which may impair diagnosis and management of glaucoma $(9,12)$. One of the important devices used to refine IOP readings due to differences in thickness and rigidity is the ocular response analyzer (5). In this study, we evaluated the changes in the IOP measurements by ocular response analyzer following Lasik procedure using M2 90 Moria microkeratome for a wide range of myopic and astigmatic ablation depths, to refine IOP for glaucoma diagnosis and management. Shin J et al., in a 2015 study involved forty eyes from 20 patients who underwent treatment for myopia using a femtosecond laser for flap creation, found that at one month after Lasik, there was a significant reduction in the IOP measurement with respect to the IOPcc ($0.67 \pm 2.07 \mathrm{~mm} \mathrm{Hg}), \operatorname{IOPg}(=-3.92 \pm 2.19 \mathrm{~mm} \mathrm{Hg})$, and Goldmann applanation tonometer (GAT) $(=-2.6 \pm 2.51)$. It was revealed that the $\mathrm{CH}$ and CRF are statistically significant predictors of IOPcc, IOPg, and GAT $(\mathrm{p}<0.000)(14)$. Shousha SM, et al. published a study of 20 eyes with age ranged from 20-50 years that had undergone Lasik for moderate myopia between -2 and -6 Diopters in which the IOP was measured preoperatively and again postoperatively using Goldmann applanation and air puff tonometry, ORA corneal compensation, and Pentacam cor $\neg$ rection. They found that compared with preoperative values, postoperative IOP mea $\neg$ sured by the four methods was significantly lower. Regarding the IOPcc, the values decreased from a mean of $18.4 \mathrm{~mm}$ (range of 11.1 to 21.9) preoperatively to $16.2 \mathrm{mmHg}$ (range of 10.2 to 19.7 ) postoperatively with an average reduction of $-1.6 \mathrm{mmHg}$ (range -3.5 to1.3). The difference was statistically significant when IOP was measured using Goldmann applanation and air puff tonometry compared with the ORA corneal compensation and Pentacam methods ( $\mathrm{P}<0.001)(12)$. In Our study using an ocular response analyzer, evaluating cases undergoing Lasik using M2 90 moria microkeratome; the IOPg decreased from a mean value of $17.1 \pm 2.75$ preoperatively to $12.26 \pm 2.81$ post-Lasik with t-test showing a highly significant reduction $(\mathrm{p}<0.01)$. TheIOPcc decreased from a mean value of $18.03 \pm 2.88$ preoperatively to $15.80 \pm 2.88$ post-Lasik with t-test showing a statistically significant reduction $(\mathrm{p}<0.05)$ and these values are close to values obtained by Shousha SM, et al.; however they don't measure IOPg in their study. The CH decreased from a mean value of $9.89 \pm 1.27$ preoperatively to $7.9 \pm 1.39$ post-Lasik) with t-test showing a statistically significant reduction $(\mathrm{p}<0.05)$. The CRF decreased from a mean value of $10.21 \pm 1.31$ preoperatively to $7.58 \pm 1.32$ post-Lasik) with t-test showing a highly significant reduction $(\mathrm{p}<0.01)$. The average post- Lasik reduction in IOPg was $4.84 \pm 2.82 \mathrm{mmHg}$ which is similar to results obtained by Shin J et al (2015). The average post-Lasik reduction in IOPcc was $2.23 \pm 3.51 \mathrm{mmHg}$ and this reduction was larger than that obtained by Shin J et al (2015) and Shousha SM, et al. who studied a smaller range of myopic correction and therefore a smaller ablation depth. The post-Lasik reduction of IOPg showed a statistically significant correlation $(p<0.05)$, between both ablation depth and preoperative spherical equivalent, with a non-significant correlation $(\mathrm{p}>0.05)$ between post-Lasik reduction of both $\mathrm{CH}$ and CRF. The postLasik reduction of IOPcc showed a non-significant correlation ( $>0.05)$, between ablation depth, preoperative spherical equivalent $\mathrm{CH}$ and CRF. Our results, that showed no correlation between the post-Lasik reduction of IOPg as well asIOPcc and both of Corneal hysteresis $(\mathrm{CH})$ and $\mathrm{CRF}$ (which does not agree with results obtained by Shin J et al.), were probably related to the wider ablation depths involved in our study. It seems therefore, that the reduction in the post-Lasik values of IOPcc by the ocular response analyzer is related mainly to reduction in corneal biomechanical stability by the thin flap creation rather than by the ablation depth ( contrary to IOPg and similar tools), which makes Corneal-Compensated Intraocular Pressure a valuable tool for IOP measurement in post-Lasik patients for the sake of glaucoma diagnosis and management, because in many cases, accurate preoperative refraction as well as Lasik ablation depth data may not be accessible.

\section{Conclusions}

Following Lasik procedure using thin flap technique (i.e. M2 90 Moria microkeratome), the IOPcc values by ORA were closer to the preoperative values than the IOPg values, and the reduction of IOP was not affected by ablation depth (i.e. preoperative spherical equivalent). Therefore, it is advisable to use the IOPcc values by ORA when evaluating post-Lasik patients for glaucoma diagnosis and management, but with the addition of the average value for post-Lasik reduction which, in the study, was $2.23 \pm 3.51 \mathrm{mmHg}$.

\section{Acknowledgments:}

This paper was extracted from the author's postgraduate thesis with acknowledgments for the Refractive Unit in the Research Institute of Ophthalmology, Giza, Egypt, that funded the research. 


\section{Financial disclosure:}

There is no proprietary or commercial interest in any of the materials discussed in this article.

\section{Conflict of Interest:}

There is no conflict of interest to be declared.

\section{Authors' contributions:}

All authors contributed to this project and article equally. All authors read and approved the final manuscript.

\section{References:}

1) Grødum K, Heijl A, Bengtsson B. A comparison of glaucoma patients identified through mass screening and in routine clinical practice. Acta Ophthalmol Scand. 2002; 80(6): 627-31. doi: 10.1034/j.16000420.2002.800613.x. PMID: 12485284.

2) Kniestedt C, Punjabi O, Lin S, Stamper RL. Tonometry through the ages. Surv Ophthalmol. 2008; 53(6): 568-91. doi: 10.1016/j.survophthal.2008.08.024. PMID: 19026320.

3) Doughty MJ, Zaman ML. Human corneal thickness and its impact on intraocular pressure measures: a review and meta-analysis approach. Surv Ophthalmol. 2000; 44(5): 367-408. doi: 10.1016/S00396257(00)00110-7. PMID: 10734239.

4) Harada Y, Hirose N, Kubota T, Tawara A. The Influence of Central Corneal Thickness and Corneal Curvature Radius on The Intraocular Pressure as Measured By Different Tonometers: Noncontact and Goldmann Applanation Tonometers. J Glaucoma. 2008; 17(8): 619-25. doi: 10.1097/IJG.0b013e3181634f0f. PMID: 19092456.

5) Medeiros FA, Weinreb RN. Evaluation of the influence of corneal biomechanical properties on intraocular pressure measurements using the ocular response analyzer. J Glaucoma. 2006; 15(5): 364-70. doi: 10.1097/01.ijg.0000212268.42606.97. PMID: 16988597.

6) Wong TT, Wong TY, Foster PJ, Crowston JG, Fong CW, Aung T. The relationship of intraocular pressure with age, systolic blood pressure, and central corneal thickness in an asian population. Invest Ophthalmol Vis Sci. 2009; 50(9): 4097-102. doi: 10.1167/iovs.08-2822. PMID: 19458324.

7) Liu J, Roberts CJ. Influence of corneal biomechanical properties on intraocular pressure measurement: quantitative analysis. J Cataract Refract Surg. 2005; 31(1): 146-55. doi: 10.1016/j.jcrs.2004.09.031. PMID: 15721707.

8) Schmack I, Auffarth GU, Epstein D, Holzer MP. Refractive surgery trends and practice style changes in Germany over a 3-year period. J Refract Surg. 2010; 26(3): 202-8. doi: 10.3928/1081597X-20090515-05. PMID: 20229953.

9) Chang DH, Stulting RD. Change in intraocular pressure measurements after LASIK the effect of the refractive correction and the lamellar flap. Ophthalmology. 2005; 112(6): 1009-16. doi: 10.1016/j.ophtha.2004.12.033. PMID: 15882906.

10) Pepose JS, Feigenbaum SK, Qazi MA, Sanderson JP, Roberts CJ. Changes in corneal biome $\neg$ chanics and intraocular pressure following LASIK using static, dynamic, and noncontact tonometry. Am J Ophthalmol. 2007; 143(1): 39-47. doi: 10.1016/j.ajo.2006.09.036. PMID: 17188041.

11) Sullivan-Mee M, Billingsley SC, Patel AD, Halverson KD, Alldredge BR, Qualls C. Ocular Response Analyzer in subjects with and without glaucoma. Optom Vis Sci. 2008; 85(6): 463-70. doi: 10.1097/OPX.0b013e3181784673. PMID: 18521025.

12) Shousha SM, Abo Steit MA, Hosny MH, Ewais WA, Shalaby AM. Comparison of different intraocular pressure measurement techniques in normal eyes, post surface and post lamellar refractive surgery. Clin Ophthalmol. 2013; 7: 71-9. doi: 10.2147/OPTH.S37978. PMID: 23326186 , PMCID: PMC3544333.

13) Luce D. Methodology for Corneal Compensated IOP and Corneal Resistance Factor for An Ocular Response Analyzer. Invest Ophthalmol Vis Sci. 2006; 47(13): 2266.

14) Shin J, Kim TW, Park SJ, Yoon M, Lee JW. Changes in biomechanical properties of the cornea and intraocular pressure after myopic laser in situ keratomileusis using a femtosecond laser for flap creation determined using ocular response analyzer and Goldmann applanation tonometry. J Glaucoma. 2015; 24(3): 195-201. doi: 10.1097/IJG.0b013e31829da1ec. PMID: 23807345. 